
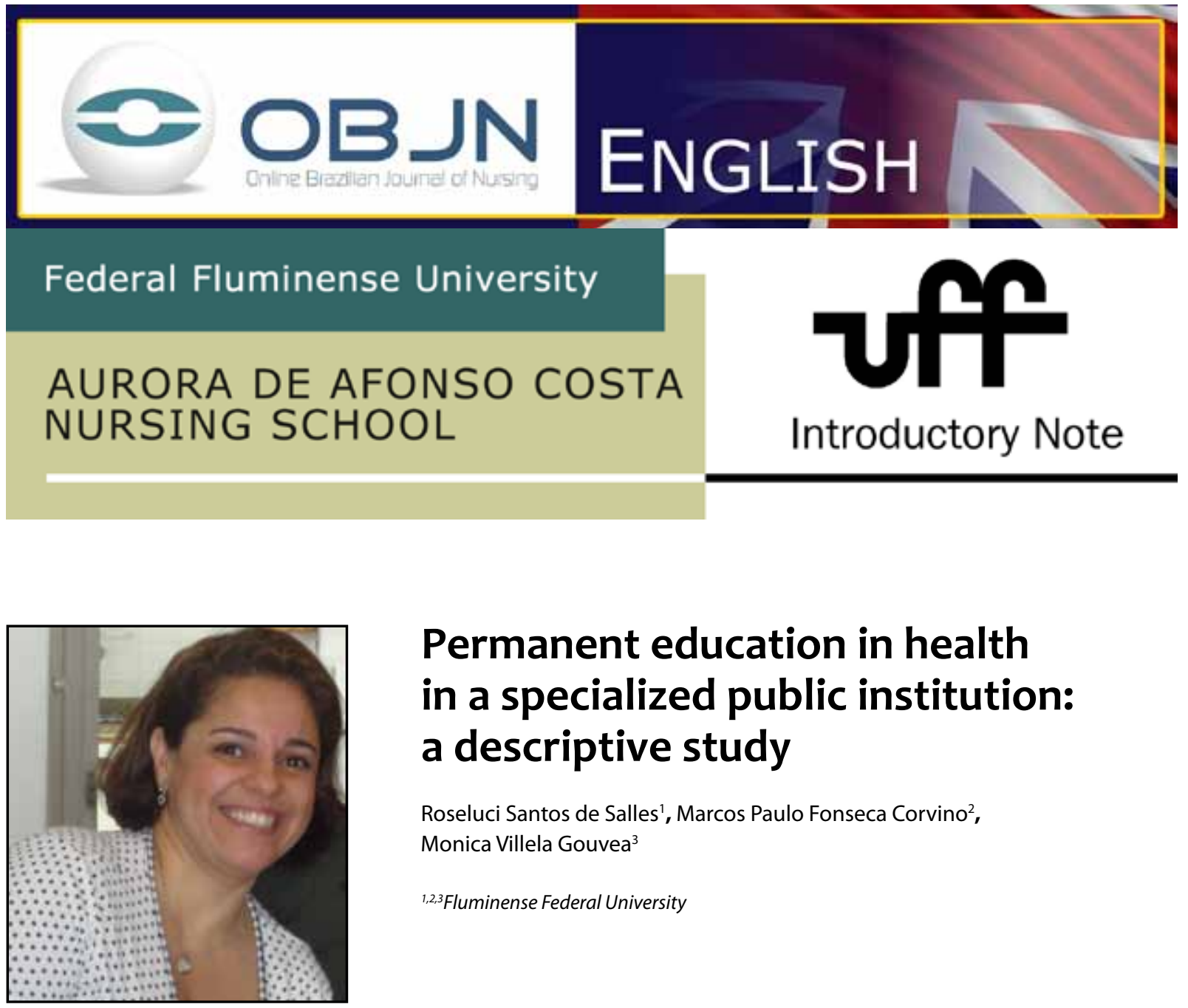

\title{
Permanent education in health in a specialized public institution: a descriptive study
}

\author{
Roseluci Santos de Salles', Marcos Paulo Fonseca Corvino², \\ Monica Villela Gouvea ${ }^{3}$ \\ 1,2,3Fluminense Federal University
}

\section{ABSTRACT}

Aim: to analyze the Permanent Education in Health activities (EPS, in Portuguese) in a medium and high complexity unit; to identify the topics of multidisciplinary interest based on the daily questions raised by different professionals; to propose educational strategies that strengthen the interdisciplinary bonds of the institutional culture. Method: this is a descriptive, exploratory study, using a qualitative approach, which targets a population of professionals from many areas. The data will be collected between September and October 2013, from focal groups and through observational participation. The analysis of the data collected will follow the approach established by Bardin. It is expected to mobilize the professionals to expand and reinforce the EPS processes in the unit.

Descriptors: Continuing Education; Quality of Health Care; Hospital Care. 


\section{PROBLEM SITUATION AND ITS SIGNIFICANCE}

Permanent Education in Health (EPS, in Portuguese) is a strategy that considers healthcare service as an educative axis, and questions the structures of pedagogical practices ${ }^{(1)}$. The construction of shared knowledge based on such practice permits the maintenance of updated health teams, with a focus on the quality of the healthcare service provided. Therefore, it is necessary that the educational processes of the professionals occur on an on-going basis in order to assist them during decision-making, to improve care and to develop the assistance provided to the final user. In order to assist patients in a specialized center of the Brazilian Unified Health System, complex interdisciplinary interventions are needed according to the professional qualification proposals as described in the permanent education policy of the Brazilian Ministry of Health ${ }^{(2)}$, which connects to the institution researched in this study. This study starts from the assumption that there are topics related to interdisciplinary aspects that are intrinsic to permanent education, and that need to be better studied in order to assist the goal of achieving a desired quality standard in terms of assistance, as proposed by the institutional mission. The intersection between education and professional development are of great relevance to education in health, and to achieve the values and the universal role of SUS. In this sense, knowledge built based on experience can be spread through the subjects that exist within the health unit. In this context the conflicts, difficulties and actions aimed to generate information are exposed. The processes of permanent education impose on the services, the areas of training/education and on the permanent education provided by health institutions, the adoption of a problematizing pedagogical concept, whose intention is to stimulate reflection with regard to practice and the construction of knowledge to be used to and with the other ${ }^{(3)}$. Thus, it aims to create an education that is committed to change by improving the quality of healthcare.

\section{GUIDING QUESTIONS}

What are the topics to be used in permanent education that create a bond among the members of the interdisciplinary team, assisting in cooperation among them? Which educational strategies can enrich the development of permanent education that is aiming to create an interdisciplinary link?

\section{AIMS}

To analyze the actions of the EPS of the institution considered in this study; to identify the topics of interdisciplinary interest based on the routine questions raised by different professionals; to propose educational strategies that strengthen interdisciplinarity as an institutional culture.

\section{ASSUMPTION}

This study is based on the assumption that EPS is a facilitating strategy with regard to interdisciplinary work, promoting and supporting the systematization of permanent qualifications in healthcare.

\section{METHOD}

This is a descriptive study, adopting an exploratory and qualitative approach, to be per- 
formed in a healthcare unit of medium and high complexity located in the municipality of Rio de Janeiro, Brazil. The population included in this study will be composed of selected professionals based on criteria of educational background, position, time working in the institution and the level of responsibility with regard to managerial, educational or assisting processes. Any professionals that are away on vacation or on medical leave during the period of data collection will be excluded from this study. The target population is predicted to be around 20 professionals, including technicians and undergraduates who are involved in interdisciplinary healthcare service in the health unit. The data will be collected in September and October 2013 through the use of focal groups and observational participation. The meetings will be documented through notes kept in a field journal. The data analysis will be undertaken using the content analysis method proposed by Bardin.

With regard to the ethical aspects, we highlight that this study will follow the requirements described on Resolution 466/12 of the Brazilian National Health Council, especially when it mentions the Directives and Standards that Rule Researches Involving Human Beings, being approved by the Ethics in Research Committee, of Antonio Pedro College Hospital (CAAE 10004012.3.0000.5243).

\section{REFERENCES}

1. Dicionário da Educação Profissional em Saúde [homepage in the internet]. Educação permanente em saúde [cited 2013 Apr 5]. Available from: http://www.epsjv.fiocruz.br/dicionario/ verbetes/edupersau.html

2. Ministério da Saúde (Brasil). Portaria № 1996/ GM/MS, de 20 de agosto de 2007. Dispõe sobre as diretrizes para a implementação da Política Nacional de Educação Permanente em Saúde e dá outras providências. Diário Oficial da União 22 ago 2007; Seção 1.

3. Godinho, JSL, Tavares, CMM. The permanent education in intensive care units: a review article. Online braz j nurs [Internet]. 2009 Aug [cited 2013 Aug 03]; 8 (2): [about 4 p.]. Available from: http:// www.objnursing.uff.br/index.php/nursing/article/view/j.16764285.2009.228. doi:http://dx.doi. org/10.5935/1676-4285.20092288

PROJECT DATA

Dissertation project of the Professional Master Program of Education in Health: Interdisciplinary Teaching Education to SUS.

Tutor: Marcos Paulo Fonseca Corvino

Co-tutor: Monica Villela Gouvea

Received: 30/08/2013

Revised: 06/09/2013

Approved: 15/09/2013 